\title{
From sleep spindles of natural sleep to spike and wave discharges of typical absence seizures: is the hypothesis still valid?
}

\author{
Nathalie Leresche $\cdot$ Régis C. Lambert . \\ Adam C. Errington • Vincenzo Crunelli
}

Received: 18 May 2011 /Revised: 22 July 2011 /Accepted: 1 August 2011 /Published online: 23 August 2011

(C) Springer-Verlag 2011

\begin{abstract}
The temporal coincidence of sleep spindles and spike-and-wave discharges (SWDs) in patients with idiopathic generalized epilepsies, together with the transformation of spindles into SWDs following intramuscular injection of the weak GABAA receptor (GABAAR) antagonist, penicillin, in an experimental model, brought about the view that SWDs may represent 'perverted' sleep spindles. Over the last 20 years, this hypothesis has received considerable support, in particular by in vitro studies of thalamic oscillations following pharmacological/genetic manipulations of GABAARs. However, from a critical appraisal of the evidence in absence epilepsy patients and well-established models of absence epilepsy it emerges that SWDs can occur as frequently during wakefulness as during sleep, with their preferential occurrence in either one of these behavioural states often being patient dependent. Moreover, whereas the EEG expression of both SWDs and sleep spindles requires the integrity of the entire cortico-thalamo-cortical network, SWDs initiates in cortex while sleep spindles in thalamus. Furthermore, the hypothesis of a reduction in GABAAR function across the entire cortico-thalamo-cortical network as the basis for the transformation of sleep spindles into SWDs is no longer tenable. In fact, while a decreased GABAAR function may be present in some cortical layers and in the reticular
\end{abstract}

This article is published as part of the Special Issue on Sleep.

N. Leresche $(\bowtie) \cdot$ R. C. Lambert

UPMC Université Paris 6, UMR7102 CNRS,

Paris, France

e-mail: nathalie.leresche@snv.jussieu.fr

R. C. Lambert • A. C. Errington • V. Crunelli

Neuroscience Division, School of Biosciences, Cardiff University, Museum Avenue,

Cardiff, UK thalamic nucleus, both phasic and tonic GABAAR inhibitions of thalamo-cortical neurons are either unchanged or increased in this epileptic phenotype. In summary, these differences between SWDs and sleep spindles question the view that the EEG hallmark of absence seizures results from a transformation of this EEG oscillation of natural sleep.

Keywords Epilepsy $\cdot$ Cortex $\cdot$ Thalamus $\cdot$ Nucleus reticularis thalami $\cdot$ GABA receptors

Numerous clinical observations indicate the presence of complex bidirectional interactions between sleep and epilepsy $[10,19,57]$. In particular, spike and wave discharges (SWDs), the electrographic hallmark of typical absence seizures ${ }^{1}$ [26], which are an integral component of several idiopathic generalized epilepsies, have been reported to occur preferentially during the light stages of non-rapid eye movement sleep (NREM) where the majority of sleep spindles are observed (Fig. 1A) [49-51]. This high temporal coincidence between sleep spindles and SWDs, together with the transformation of sleep spindles into SWDs following intramuscular injection of penicillin (a weak GABAA antagonist) in the cat $[2,31,33$, $55,56]$ and other experimental evidence following manipulations of GABAA receptors (GABAARs) [6, 20, 43, 105], has brought about and consolidated the view of SWDs as 'perverted' sleep spindles [12, 33, 50, 54, 68].

However, absence seizures can occur as frequently during wakefulness as during light NREM sleep, and the issue of why and how SWDs are also generated during the former behavioural state has not received the necessary critical

\footnotetext{
${ }^{1}$ Typical absence seizures are non-convulsive epileptic attacks that are characterized by a sudden and relatively brief impairment of consciousness which is invariably accompanied by generalized and synchronous 2.5-4 Hz SWDs in the EEG.
} 
A1

Sleep spindles

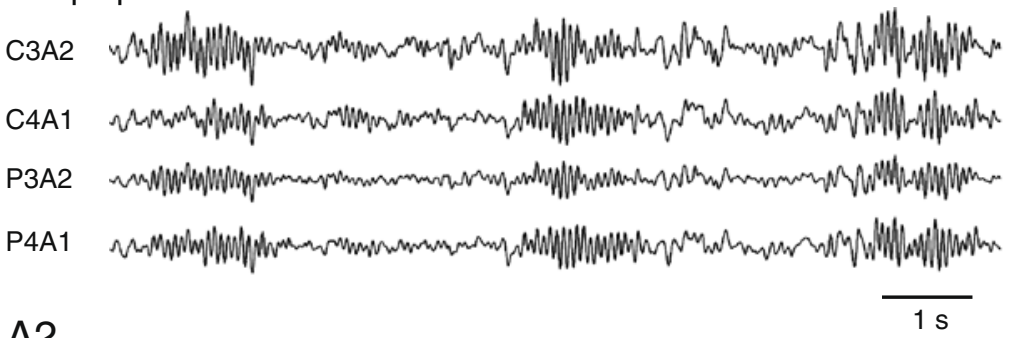

A2

SWDS

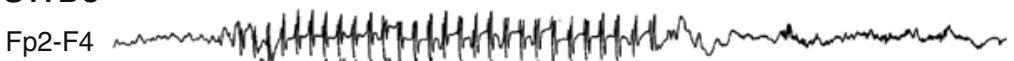

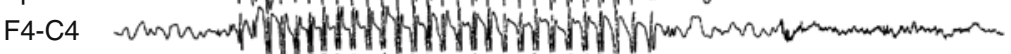

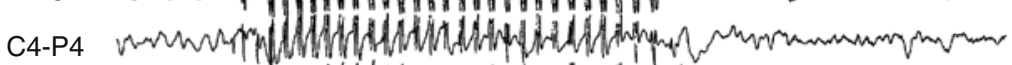

$\mathrm{F} 4-\mathrm{O} 2$
B

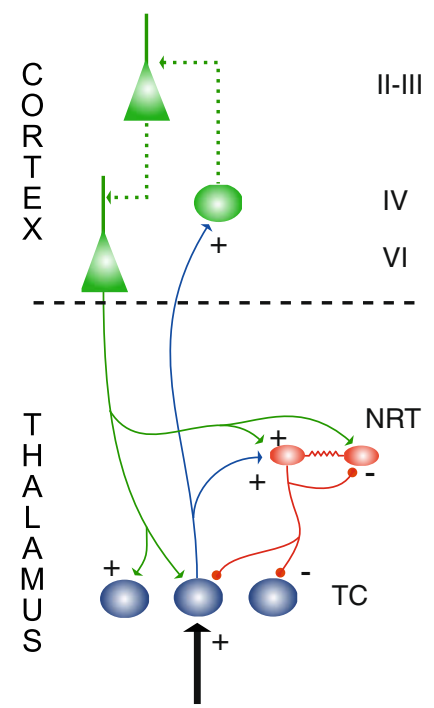

Fig. 1 Sleep spindles and spike and waves discharges (SWDs) of absence epilepsy. A1 Sleep spindles recorded during natural sleep from four standard EEG derivations in a normal subject during stage 2 of NREM sleep. 2 SWDs of childhood absence epilepsy. Video-EEG recordings from four standard EEG derivations in a 7-year-old girl with frequent daily absence seizures show the typical features of regular and rhythmic 3-Hz SWDs. (Reproduced with permission from

attention. Moreover, it is unclear whether the temporal association between sleep spindles and SWDs does really imply a causal relationship between these two EEG oscillations and, if so, whether the suggested decrease in GABAAR function does underlie the cellular and network abnormalities involved in the transformation of sleep spindles into SWDs. Our aim here is to provide an appraisal of the proposed link between sleep spindles and SWDs of typical absence seizures, using a more comprehensive and critical analysis of the existing human studies as well as of in vivo and in vitro investigations in well-established experimental models of absence epilepsy ${ }^{2}$ than in some recent reports $[12,42]$.

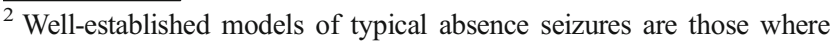
conclusive evidence is available of their behavioural, electrographic and pharmacological (i.e. sensitivity to anti-absence drugs) similarities with the human condition. Models to be considered in this review include: (a) polygenic inbred rat models (the Genetic Absence Epilepsy Rats from Strasbourg, the Wistar Albino Glaxo strain/Rijswijk Netherland, and the Fischer 344 rats); (b) monogenic mutant mouse models (stargazer, st; lethargic, lh; tottering, tg) which together with absence seizures present additional neurological phenotypes; (c) transgenic mouse models (succinic semialdehyde dehydrogenase knockout mice and GABAtransporter $1 \mathrm{KO}$ mice); and (d) two pharmacological models: the intramuscular injection of penicillin in the cat (the FGPE model), and the systemic injection of $\gamma$-hydroxybutyric acid (the GHB model; for details, see Table 1 in [26]). Note that whereas in the vast majority of childhood absence epilepsy patients seizures remit by their late teens, in all genetic absence models once initiated absence seizures continue for the entire life span of the animals
}

\section{Occurrence of SWDs across the wake-sleep cycle}

Typical absence seizures are present in many idiopathic generalized epilepsies, but they represent the only phenotype in childhood absence epilepsy. Many difficulties exist in recruiting sufficiently large cohorts with a homogeneous epileptic phenotype (but see [4, 52, 72]). Nevertheless, it is regrettable that only a few studies $[8,75]$ have so far investigated the relationship between typical absence seizures and sleep in childhood absence epilepsy patients, where the potential link between this epileptic phenotype and sleep spindles could be assessed more directly and without potential contamination by the concomitant presence of other types of seizures. Indeed, few of the studies that enrolled cohorts with diverse idiopathic generalized epilepsies have attempted to analyse the results with respect to the type of epilepsy $[19,40,51,60,73,110]$. Moreover, since it is well-known that some antiepileptic drugs are capable by themselves of altering the overall wake-sleep balance or even selected components of sleep [84], another important drawback of some human investigations is the lack of information on the patient medication or indeed the fact that the enrolled cohorts were not free from antiepileptic drugs. Finally, the interpretation of sleep studies in patients with SWDs is complicated by the fact that sleep abnormalities are known to represent a serious and common behavioural problem in normal children and are clearly 
exacerbated in those with (idiopathic) epilepsy $[9,11,17$, 19, 109]. Overall, therefore, the conclusions on the preferential occurrence of SWDs during different components of the sleep-wake cycle in humans should be considered with some caution.

Though clear indications of an association between light sleep and SWDs had previously been reported $[55,56]$, it was the seminal work of Kellaway and co-workers [51] that, using continuous long-term recordings in 13 drug-free and six treated patients with different idiopathic generalized epilepsies, fully highlighted the tight temporal association between SWDs and sleep spindles and the prevalent occurrence of these epileptic paroxysms during NREM sleep. It is unfortunate, however, that one finding of this study has systematically been overlooked by old and recent reviews of this research field $[34,42,54,68]$, i.e. that 'rare' cases were identified of patients who showed an exclusive appearance of absence seizures during wakefulness (see page S22 and figure 12 in [50]). Niedermeyer's work, while confirming these observations also highlighted the occurrence of SWDs at times of behavioural state transition, i.e. at sleep onset and at time of awakening [74]. Many more recent studies have confirmed the preferential presence of SWDs at transitional states and in light NREM sleep and the modifications in the morphology and frequency of SWDs during sleep stages 3 and 4 [37], but have also clearly indicated their occurrence during (mostly quiet) wakefulness $[8,37,40]$. It is interesting to note that in these studies, as previously reported by Kellaway [49, 50], the difference between wake and sleep state occurrence of SWDs is very often patient dependent more than related to subsequent day-night cycles in the same patient. Finally, a recent large study on 77 children (mean age $6.4 \pm 5.4$ years) with different types of idiopathic generalized epilepsy has shown that SWDs preferentially (91\%) occur during wakefulness, with a large peak between 9 a.m. and noon, though a much smaller peak is also evident between 6 p.m. and midnight which is independent from the patient being awake or asleep [110]. In another study, in three drug-free children with SWDs there were fewer sleep spindles in stage 2 sleep but a similar total amount of spindles during the entire night compared to the control age-matched group [73]. However, in children that responded to pharmacological treatment there was no difference in the amount of sleep spindles in stage 2 compared to the control group [73]. Although these data may suggest that spindles in stage 2 are being 'replaced' by SWDs, thus indirectly supporting the spindle-SWDs transformation hypothesis, confirmation of these results in a larger untreated patient cohort is needed. In conclusion, therefore, the human studies strongly support the view that SWDs are present during both wakefulness and NREM sleep, and that sleep spindles are not entirely suppressed in patients with absence seizures.

As far as experimental absence epilepsy is concerned, meaningful data on the temporal correlation of spindles and SWDs can only be gathered from genetic models. No data are available on the temporal distribution of SWDs across the wake-sleep cycle of monogenic mutant models of absence seizures (e.g. st, $l h, t g$ ). In the Wistar Albino Glaxo (WAG) rats, $56 \%$ of SWDs occur during the wake state (15\% and $39 \%$ during active and quiet wakefulness, respectively) and $46 \%$ during sleep (35\% in non-REM and $11 \%$ in REM sleep) [88]. In Fisher 344 rats, SWDs (or High Voltage Spindles as they used to be called in this model) are observed only during awake immobility and are quite distinct from sleep spindles, which are of lower amplitude and rarely observed in the immobile awake condition [46]. In the genetic absence epilepsy rats from Strasbourg (GAERS) rats, 66\% of SWDs starts and ends during quiet immobile wakefulness, $27 \%$ during transition between wakefulness and slow-wave sleep $(20 \%$ from wakefulness to slow-wave sleep and $7 \%$ from slow-wave sleep to arousal) and less than $7 \%$ is entirely contained within slow-wave sleep $[59,66]$. The majority of SWDs in this rat model emerge from a short episode $(0.5$ to $3 \mathrm{~s})$ of medium-voltage $5-9 \mathrm{~Hz}$ oscillations [80, 81]. Interestingly, such oscillations in the theta frequency band, which should not be confused with the classical theta rhythm of limbic regions, are also recorded in control non-epileptic rats during quiet immobile wakefulness, but not before sleep spindles, suggesting marked differences in the initial conditions of the underlying neuronal network prior to the expression of either sleep spindles or SWDs. An increased power in the theta frequency band which occurs just before the development of a SWD has also been observed in local field potential recordings in cortex and thalamus of WAG rats [86, 102]. Differently from the GAERS model, however, in WAG rats this increase in theta power is accompanied by an enhanced alpha and delta band power $[86,102]$, suggesting that the potential increase in theta oscillations prior to the appearance of a SWD in absence models may not be selective for this low frequency band.

Within the context of sleep and absence seizures, other recent key observations have been the deficiency in sleeppromoting mechanisms in WAG rats and the ability of partial activation of a sleep-promoting area (ventrolateral and median preoptic nuclei) to elicit absence-like paroxysms in normal rats [95]. Although the effect of antiabsence drugs against these absence-like EEG activity were not tested, these results point to an insufficiency/inefficiency in sleep-promoting mechanisms as one of the underlying causes of absence seizures. Indeed, WAG rats show fewer SWDs at the start of the light phase of sleep, when sleep 
pressure is at its highest, whereas they occurrence increases towards the end of the light phase [101].

In summary, these human and experimental results strongly indicate that far from being strictly associated with a defined behavioural state, and in particular with stage 2 sleep where the vast majority of sleep spindles are observed, SWDs do occur as frequently during quiet wakefulness as during (the light stages of) NREM sleep. Moreover, the preferential occurrence of SWDs either in the wake or sleep state is strongly patient dependent. Therefore, any proposed pathophysiological mechanism of absence seizures should fully account for their development during both the wake and sleep states and be able to explain how both in humans and genetic animal models sleep spindles and SWDs can co-exists side-by-side during certain behavioural stages. Indeed, the proposed deficiency in sleep-promoting mechanisms may well account for these observations. Lastly, the question remains of whether the lack of consciousness in a sleeping patient during SWDs is similar to the temporary loss of consciousness that is experienced by awake patients during typical absence seizures, particularly in view of the fact that in the latter condition some subjects can recollect events linked to some (though not all) sensory modalities [77].

\section{Sleep spindles and SWDs generation: a common neuronal network but a different initiation site}

The initial proposal that SWDs may represent a paroxysmal transformation of sleep spindles originated from the experimental observation that intramuscularly injected penicillin can transform the $10-15 \mathrm{~Hz}$ sleep spindle oscillations into 4-5 Hz SWDs in felines (FPGE) [33, 34, $56,83]$, though evidence in support of an origin from cortico-thalamo-cortical networks were evident in earlier studies, in particular from Jasper's group [44]. As mentioned above, at about the same time Kellaway's work [4951] was providing support to this view by showing a tight temporal association between sleep spindles and SWDs. These findings, therefore, led to the proposition that both electrographic signatures arise from the same neuronal circuit [34, 67, 92], and Beenhakker and Huguenard [12] have recently re-branded the thesis that the normal spindlegenerating circuitry, i.e. the cortico-thalamo-cortical network, is hijacked to generate SWDs. However, we will here argue that while the original idea that the cortico-thalamocortical network is responsible for the generation of both sleep spindles and SWDs is still valid, the recent proposals of (a) a cortical initiation of sleep spindles and (b) a compromised thalamic GABAAR function as a necessary condition for SWDs generation [12] are not defensible, since they are based on a selective choice interpretation of the available evidence, as explained in this and the following section, respectively.

The expression of human typical absence seizures requires coordinated activity in reciprocally connected thalamic and cortical territories, as revealed by some old invasive studies and modern non-invasive imaging investigations, with some of the latter focusing on childhood absence epilepsy patients where, as mentioned before, these seizures represent the only pathological phenotype $[4,35$, $52,72,100,108]$. These studies have also confirmed the lack of involvement of other brain areas, including hippocampus, cerebellum and limbic regions, though the anterior thalamus and the precuneate nucleus have recently been highlighted as regions of potential interest $[100,103]$. Importantly, the almost exclusive involvement of corticothalamo-cortical networks in the generation of typical absence seizures has also been widely confirmed in experimental absence models [69, 104].

Against the common belief that absence seizures are generalized from their very start, one of the most important recent discoveries in the field has been the identification of a cortical 'initiation site' of SWDs. Thus, in agreement with some old data using standard EEG configurations, recent high density EEG studies in patients with different idiopathic generalized epilepsy have shown the presence of SWDs in discrete, mainly frontal and parietal cortical regions before they appear over the rest of the cortical mantle [39]. These findings have been confirmed in MEG and fMRI studies of children with a pure typical absence seizure phenotype $[4,72,107]$. In particular, an increased BOLD signal can be detected in frontal and parietal cortex more than $5 \mathrm{~s}$ before any clinical signs of the seizure are manifested, and then spreads to other cortical sites and to the thalamus [4].

Interestingly, the cortical site of initiation can be different among various patients, but in a given patient it is maintained in successive seizures and across days [72]. The presence of a putative cortical 'initiation site' for typical absence seizures has also been shown in the WAG and GAERS models where, differently from human absence epilepsy however, it is consistently located in the perioral region of the primary somatosensory cortex $[65,69,82]$. Whether a similar site is present in the monogenic mutant models $s t, l h$ and $t g$ as well as in different $\mathrm{KO}$ mice with an absence epilepsy phenotype remains to be determined.

The only study that has systematically compared sleep spindles and SWDs using current source density analysis and large neuronal ensemble recordings in the neocortex has shown that these two brain rhythms possess a similar pattern of cortical sinks, sources and unit firing, which only differ in their relative strength and timing, as well as in a spatially more restricted cortical spread of spindles com- 
pared to SWDs [48]. In contrast to SWDs, however, the essential network that is currently believed to initiate sleep spindles consists of two groups of mutually connected thalamic neurons, the glutamatergic thalamocortical (TC) neurons and the GABAergic inhibitory neurons of the nucleus reticularis thalami (NRT; Fig. 1B), as indicated by several key experimental in vivo and in vitro studies [42, $43,93]$. Of course, because of the extensive thalamocortical and corticothalamic projections, it is the entire corticothalamo-cortical network that ultimately determines the expression and spatio-temporal coherence of sleep spindle oscillations over the cortical mantle as measured from EEG electrodes [16, 21, 23].

As mentioned before, it has recently been suggested that sleep spindle waves are initiated by a cortical input/volley to thalamic regions [12]. This argument stems from the fact that since sleep spindles are most commonly observed during the UP states of the slow $(<1 \mathrm{~Hz})$ sleep oscillation of NREM sleep, which is considered to be of cortical origin $[36,38,71,99]$, then sleep spindles too are initiated by a neocortical drive to the thalamus. However, the generally accepted and simplistic explanation of the slow $(<1 \mathrm{~Hz})$ sleep oscillation as being entirely of cortical origin has recently been challenged [25], since it does not take into account the finding that both TC and NRT neurons are capable of eliciting the slow $(<1 \mathrm{~Hz})$ sleep oscillations in the absence of a cortical drive $[14,27,29,41]$. In agreement with this view, recent in vivo data from Timofeev's group have now conclusively demonstrated that the slow $(<1 \mathrm{~Hz})$ sleep oscillation in the neocortex is abolished following temporary inactivation of the somatotopic thalamic region [61]. Thus, the proposed cortical initiation of sleep spindles is not supported by currently available evidence, and the more solid explanation for sleep spindle generation does still remain the one that considers the NRT-TC network as the driver/initiator of this EEG signature of sleep.

Another interesting difference between spindles and SWDs has come from a recent investigation that analysed cortical EEG and thalamic local field potentials in freely moving, naturally sleeping WAG rats following unilateral ibotenic acid lesions of the NRT [70]. This study shows that only the rostral part of the NRT plays a role in the generation and spreading of SWDs, whereas the entire NRT is critically involved in sleep spindles. Notwithstanding the technical difficulties of selectively delivering a neurotoxin to a localized region within the peculiarly narrow and elongated shape of the NRT, these results suggest that although generated in the same corticothalamo-cortical network genetically determined SWDs and naturally occurring sleep spindles in a well-established model of absence epilepsy may be governed by different thalamic subcircuits.
In summary, the cortico-thalamo-cortical circuit is the main neuronal network that underlies the EEG expression of both sleep spindles and SWDs, but a major difference exists between sleep spindles and SWDs initiating mechanisms, with the former being of thalamic origin and the latter possessing a cortical 'initiation site', the location of which is often patient selective.

\section{Does a decreased GABAAR function underlie the transformation of sleep spindles in SWDs?}

As mentioned earlier, the hypothesis that SWDs result from aberrations of sleep spindle-generating mechanisms has mainly evolved from, and been putatively consolidated by two sets of data. Firstly, the old in vivo results from the intramuscular injection of penicillin in cats (the FPGE model) $[33,34,56]$, and secondly, the results of more recent electrophysiological in vitro studies performed in ferret thalamic slices, where the block of thalamic GABAARs was shown to transform spindle-like $10-14 \mathrm{~Hz}$ oscillations into a rhythmic activity at a frequency $(3 \mathrm{~Hz})$ similar to that of SWDs in humans [6, 105] (Fig. 2B). Because of the similarity in frequency, and because the fact that (a) penicillin is a GABAAR antagonist, (b) a number of mutations in GABAAR have been identified in families with different idiopathic epilepsies with absence seizures $[47,58,63,64,98,106]$ and (c) a decreased GABAergic inhibition is intuitively assumed to underlie epileptic paroxysms, the firing patterns and underlying ionic mechanisms observed in thalamic slices of different species during block of GABAARs have been heralded as the series of events that occur in thalamic neurons during absence seizures [6, 43, 45, 53, 105]. However, the overall intracellular voltage waveform recorded from TC neurons in thalamic slices where GABAARs had been blocked bears no resemblance to that observed in vivo in TC neurons from two well-established models (compare TC neurons activities in vitro and in vivo in cat and GAERS in Fig. 2B). Nor could these differences be explained by differences in spindle intracellular waveform or generating mechanisms since they look very similar across species (cat and rats) and conditions (in vitro and in vivo; Fig. 1A).

More worryingly, the thalamic in vitro data have been used to support the view that absence epilepsy is characterized by a reduced GABAAR activity in the major cellular components of the cortico-thalamo-cortical network, i.e. cortical, TC and NRT neurons. However, as far as TC neurons are concerned, all findings from the wellestablished in vitro and in vivo absence epilepsy models do not support this view, since as indicated by the following pieces of independent evidence phasic and tonic GABAAR function in TC neurons is neither abolished nor decreased: 


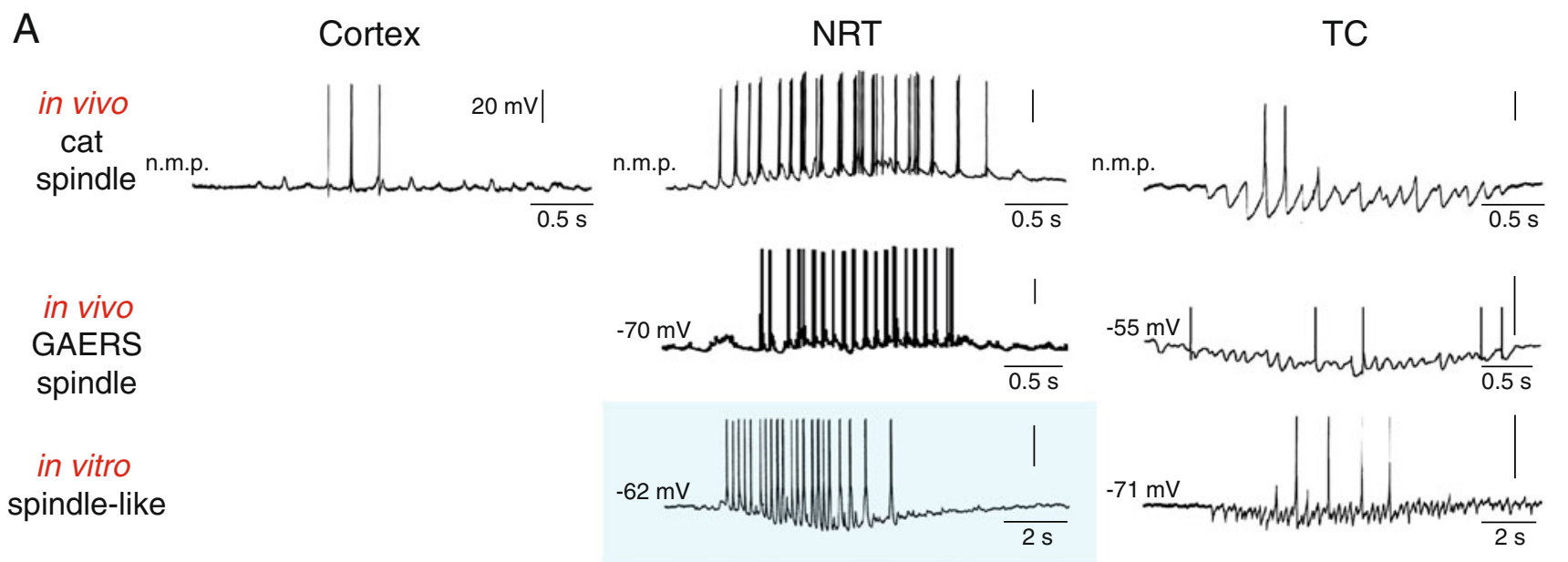

B
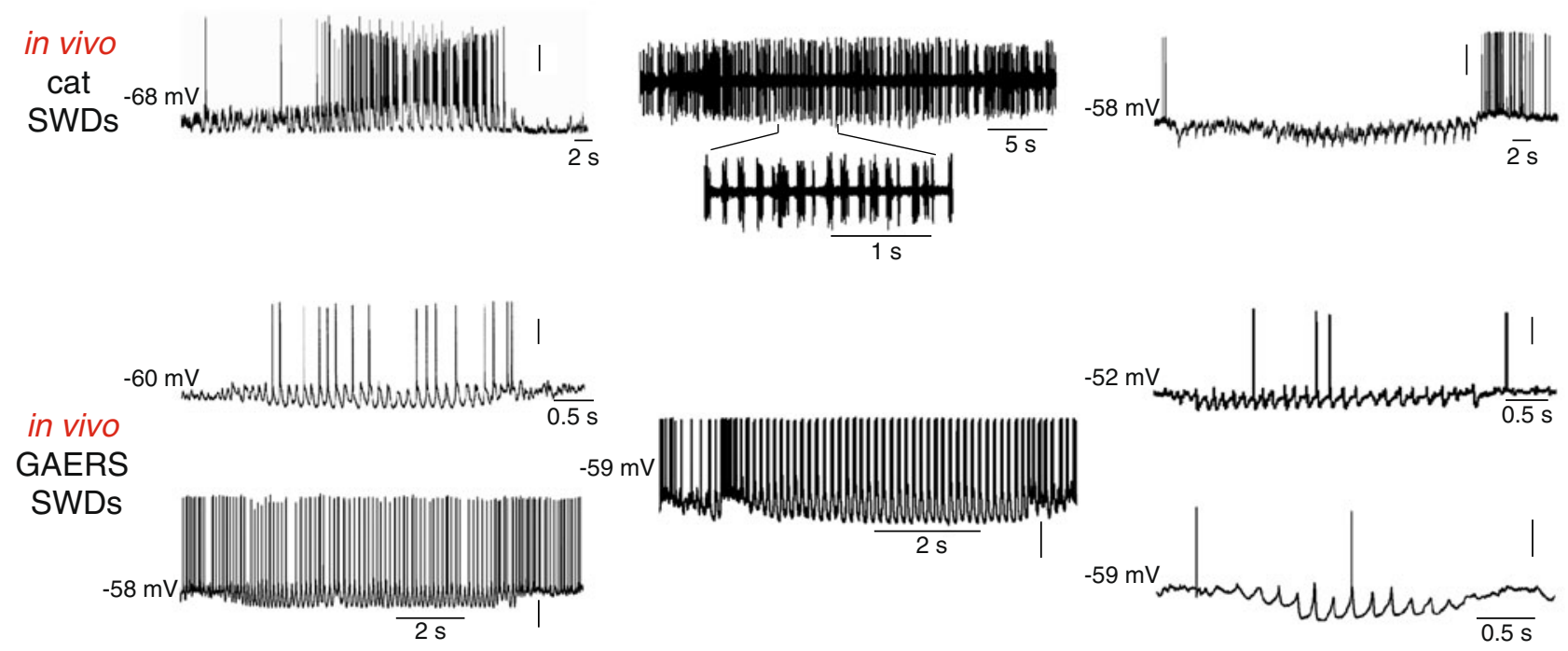

in vitro

spindle-like + bicuculline

in vitro

spindle-like + CT stim.
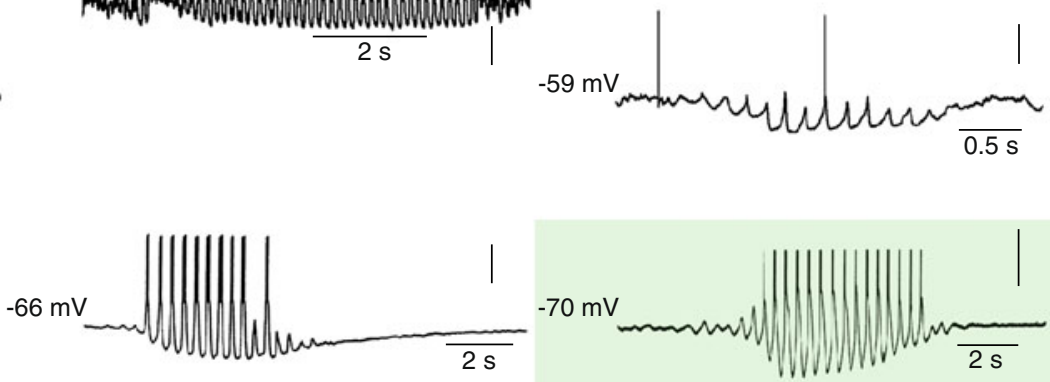

- As clearly demonstrated and thoroughly reviewed by Massimo Avoli, Pierre Gloor and George Kostopolous, the intramuscular injection of penicillin has no apparent effect on GABAergic function in TC neurons [1, 3, 34, 54]

- The direct intrathalamic injection of either penicillin [54] or the more potent GABAAR antagonist bicuculline [91] fails to elicit SWDs in the cat

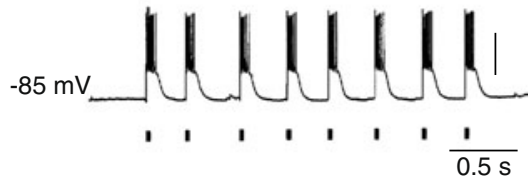

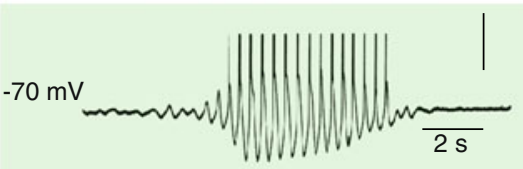



- During spontaneous SWDs the vast majority $(60 \%$ and $90 \%$ in cat and GAERS, respectively) of TC neurons in vivo shows rhythmic sequences of composite GABAA IPSPs which occur in synchrony with each spike and wave complex, indicating that these receptors are operational during absence seizures (Fig. 2B) [79, 90]

- Strong repetitive stimulation of the corticothalamic afferents in ferret thalamic slices with intact GABAAR 
Fig. 2 Intracellular membrane potential correlates of cortical, TC and NRT neuron activity during sleep spindles and spontaneous SWDs. A Intracellular recordings in vivo during sleep spindles and in vitro during spindle-like oscillations. The cat neuron (in motor precruciate cortex) shows rhythmic EPSPs at about $6 \mathrm{~Hz}$ with occasional action potentials. The NRT neuron firing is similar in the three preparations and consists of repetitive high-frequency $(200-400 \mathrm{~Hz})$ bursts of action potentials. The underlying membrane potential envelope in NRT neurons, however, is depolarizing in vivo but hyperpolarizing in vitro (blue box). The TC neuron activity is characterized by rhythmic IPSPs with occasional single, or doublets of, action potentials, some of which are generated by low threshold $\mathrm{Ca} 2+$ potential (LTCPs). In vivo spindles were recorded under barbiturate anaesthesia. n.m.p. membrane potential not reported in the original traces (reproduced with permission from Refs [94] and [105] (C) Science, Refs [80] and [7] (C) Wiley). B Intracellular or extracellular recordings in vivo during SWDs and intracellular recordings in vitro in the presence of bicuculline or during cortico-thalamic (CT) stimulations. Cortical neurons were in layer V/VI of the motor precruciate area (for cat, under ketamine xylazine) and somatosensory cortex (for GAERS, under neurolept anaesthesia). The two GAERS neurons were located outside (top trace) or within the cortical initiation site (bottom trace). In both cat and GAERS, the cortical neurons show rhythmic depolarizations underlying action potentials discharges, which occur at the characteristic SWD frequency of each model (cat, 2-2.5 Hz; GAERS, 7-9 Hz). In GAERS, note the strong firing of the neuron located in the initiation site compared to that of the neuron in an adjacent region. The activity of NRT neurons during SWDs is similar across models (cat and rat) and conditions (in vivo and in vitro), and consists of rhythmic LTCPs, each crowned by a strong high-frequency burst of action potentials. In thalamic slices, the frequency of the spindle-like oscillation (blue box in $\mathbf{A}$ ) is slowed down from 5 to $3 \mathrm{~Hz}$ while the duration of the action potential burst is markedly increased in the presence of bicuculline (green box). The activity of TC neurons in vivo and in the presence of bicuculline in vitro is drastically different. TC neurons recorded in cat and GAERS show rhythmic sequences of composite IPSPs with the occasional firing of (usually) one or two action potentials. In striking contrast, the activity recorded in the presence of bicuculline (green box) consists of regular and rhythmic LTCPs, each crowned by a high-frequency burst of action potentials. In the absence of bicuculline; however, TC neurons can express an activity similar to that of SWDs recorded in vivo when strong repetitive stimulation of corticothalamic fibres is applied in a thalamic ferret slice (yellow box). All traces are intracellular recordings except the extracellular recording from a cat NRT neuron during a SWD. Action potentials were truncated in some original traces (reproduced with permission from $[15,78,82,87,90]$ (C) Society for Neuroscience; [7, 80] (C) Wiley)

function [5, 15] leads to an activity pattern in TC neurons (see yellow box in Fig. 2B) that is similar to that recorded in vivo during SWDs in absence models

- Localized microiontophoretic application of bicuculline during SWDs drastically increases the firing of TC neurons in WAG rats in vivo, indicating that GABAARs are functional during this epileptic activity in an inbred model [89]

- The overwhelming majority of data from in vivo models indicates either no change or an increase in phasic GABAAR-mediated inhibition (i.e. IPSPs or IPSCs) in TC neurons of sensory thalamic nuclei compared to their respective non-epileptic control strains (Fig. 3A) [13, 24, 96]

- Tonic GABAA inhibition is enhanced in TC neurons of GAERS rats, of $s t$, $t h$ and succinic semialdehyde dehydrogenase (SSADH) $-1-$ mice as well as by GHB (Fig. 3B) [24, 30]

- Systemic and intrathalamic (i.e. in the ventrobasal thalamic nucleus) injection of drugs that selectively increase tonic GABAA inhibition elicit typical absence seizures in normal animals [24], demonstrating the necessity of this form of GABAA inhibition in TC neurons for the expression of SWDs

- GABA-transporter-1 knockout mice, which express a prominent absence seizure phenotype, have an enhanced tonic GABAA current in TC neurones compared to wildtype littermates [24]

- GABAA IPSPs in TC neurons of GABAAR- $\beta 3$ subunit KO mice, which have absence seizures, are unchanged compared to wild-type littermates [45]

- The unitary conductance of GABAA IPSCs in TC neurons of an intralaminar thalamic nucleus in WAG rats is increased compared to non-epileptic rats [18]

- Mice with the human GABAA- $\gamma 2(\mathrm{R} 43 \mathrm{Q})$ mutation, which has been identified in a large Australian family [106], express spontaneous absence seizures but no change in miniature IPSCs in TC neurons [97]

Against this overwhelming set of data stands the ability of microdialysis application of bicuculline into the rat ventrobasal thalamic complex to elicit continuous $3 \mathrm{~Hz}$ waves in the somatotopic cortical area in vivo [20], a finding that has been used to support the importance of a reduced GABAAR function in the generation of SWDs [12]. This claim, however, is fully ill-founded at present, since the effect of anti-absence drugs was not tested on these $3 \mathrm{~Hz}$ cortical oscillations, and therefore we do not know whether they are SWDs. Moreover, we have known for some years that no SWDs are induced by thalamic injection of bicuculline in the cat in vivo [91].

As far as GABAAR function in NRT neurons is concerned, in an inbred rat model (GAERS) [13], in mice carrying the human GABAA- $\gamma 2$ (R43Q) mutation [97] and in mice with spontaneous mutations (DBA/2J) [96], there is either no change or an increase in intra-NRT phasic GABAA inhibition. In contrast, in GABAAR- $\beta 3$ subunit KO mice, which show absence seizures as part of a much complex phenotype, GABAA IPSCs in NRT neurons are abolished [45], and in $\alpha 3 \mathrm{KO}$ mice, which show an unexpected decrease in GHB-induced seizures, GABAA IPSCs in the NRT are increased [85]. Thus, it remains unclear which type of changes (if any) in intra-NRT phasic GABAA inhibition is a necessary condition for the expression of typical absence seizures. 


\section{Phasic GABA-A current}

A1
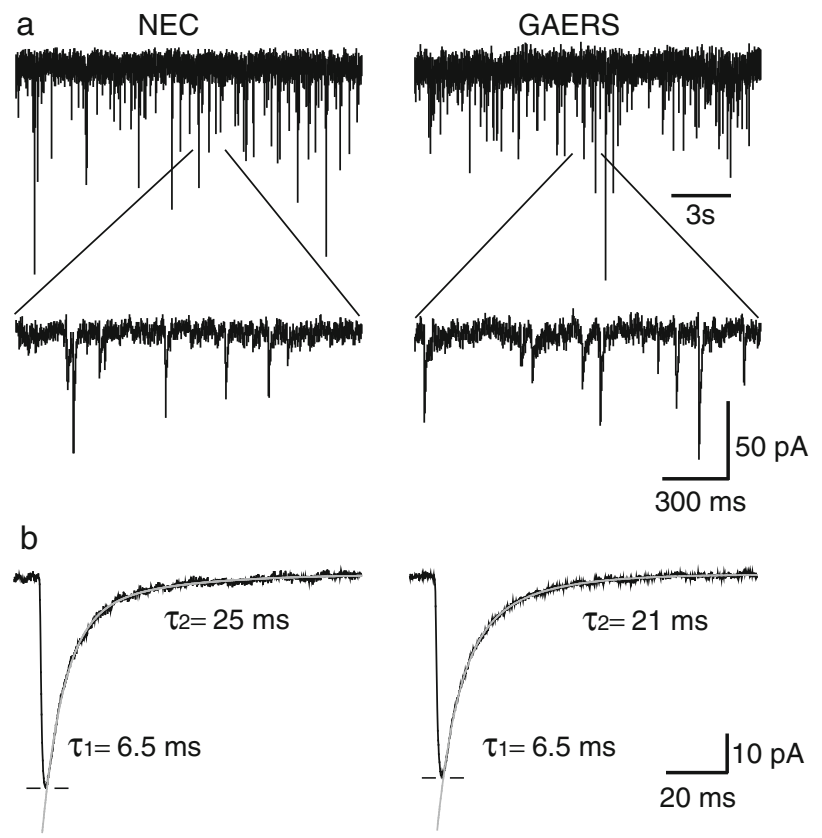

$\mathrm{A} 2$ NEC

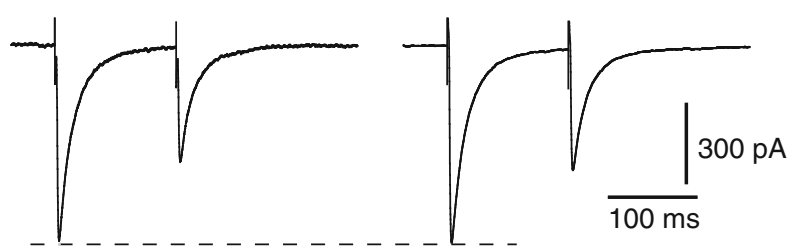

Fig. 3 Phasic and tonic GABAA inhibition in TC neurons in genetic and pharmacological models of typical absence seizures. A1 Phasic GABAA inhibition is not decreased in GAERS TC neurons. GABAA mIPSCs in TC neurons of ventrobasal nucleus slices from nonepileptic control (NEC) and GAERS rats. a Upper traces show mIPSCs, depicted at a faster time base in the lower traces. $b$ Decay kinetics measured on averaged mIPSCs from the neurons is best fitted by two exponentials and shows no difference between NEC and GAERS. A2 Paired-pulse depression of IPSCs recorded in ventrobasal TC neurons in vitro is similar between NEC and GAERS. B Tonic GABAA current is enhanced in TC neurons of rat and mouse models of typical absence seizures. B1 Current traces from ventrobasal TC neurons in vitro show a larger tonic current in GAERS rats and

As far as the neocortex is concerned, a decreased cortical GABAergic inhibition has been suggested to occur in layer $2 / 3$ regular spiking neurons [62] and in layer 5 pyramidal neurons [28] of adult WAG rats. Moreover, a slight reduction in GABAA IPSPs/IPSPCs in layer $2 / 3$ has been reported in mice carrying the human GABAA- $\gamma 2$ (R43Q) mutation [97]. However, no change is observed in mIPSCs in pyramidal cells and interneurons of cortical layer $2 / 3$ of
B1

Tonic GABA-A current


B2

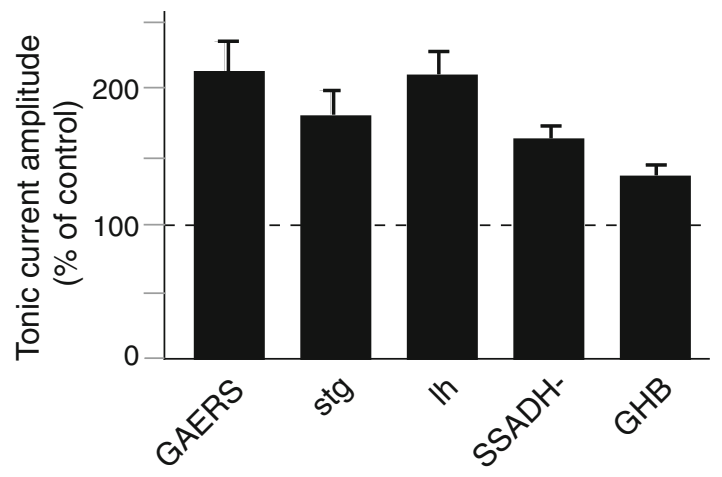

SSADH-/- mice than in respective non-epileptic control animals. Tonic current is revealed as a shift in baseline current following the focal application of the GABAA receptor antagonist $(100 \mu \mathrm{M}$ gabazine, white bars). B2 Summary histogram depicts the percentage increase of tonic GABAA current in TC neurons of GAERS, stargazer (stg), lethargic (lh) and SSADH-/- mice compared with their respective age-matched control littermates. An increased tonic GABAA current is also observed in vitro in ventrobasal TC neurons of normal Wistar rats following the application of the pro-absence drug $\gamma$-hydroxybutyric acid (GHB, $3 \mathrm{mM}$ ); reproduced with permission from [13] (C) American Physiological Society; [24] (C) Nature Publishing Group

young, pre-seizure GAERS [13], and cortical GABAergic inhibition is apparently intact in the FEPG model [32].

In summary, human and experimental evidence strongly support the view that the changes in GABAAR function in absence epilepsy are brain area selective, with a potential layer- and model-specific decrease in neocortical GABAAR function, a reduction or an increase in NRT neurons but either no change or an increase in TC neurons. Thus, the TC neuron 
mechanisms observed in thalamic slices during block of GABAARs carry no relevance to the pathophysiological mechanism of absence seizures: this, in turn, weakens the hypothesis that SWDs originate from a transformation of sleep spindles via an overall decrease in GABAAR function across the entire cortico-thalamo-cortical network.

\section{Conclusions}

The picture that emerges from the available human and experimental evidence is that SWDs occur both in the wake and sleep state and are therefore not restricted to behavioural states with a high incidence of sleep spindles. Whereas both sleep spindles and SWDs do emerge from the same neuronal circuit, i.e. the cortico-thalamo-cortical network, the initiation site of the two activities is different: thalamic for spindles and cortical for SWDs. Moreover, the majority of SWDs in experimental models appears to evolve from EEG periods with an increased power in the theta frequency band, whereas sleep spindles do not. A decreased GABAAR function, which has often been suggested to be associated with absence seizures, may be present in some neocortical layer of some absence models and possibly among NRT neurons, while in TC neurons both phasic and tonic GABAAR-mediated inhibition is either unchanged or increased in both genetic and pharmacological models. Whether these substantial differences could still be construed as to satisfy the hypothesis that sleep spindles are transformed in SWDs now appears highly doubtful.

More likely is the scenario where absence seizures arise in a discrete cortical initiation site due to paroxysmal development of normal $5-9 \mathrm{~Hz}$ oscillations which is likely to involve a cortical layer-selective reduction in GABAAR function and a potential deficiency in sleep-promoting mechanism. The resulting synchronised cortical discharge potently excites NRT neurons which respond by generating T-type Ca2+ channel-mediated high-frequency bursts of action potentials on every cycle of the SWD. The resulting strong barrages of IPSPs in TC neurons easily override cortical excitation, while the concomitant increase of ambient GABA levels, due to reduced GABA uptake by GABA transporter 1, enhances tonic inhibition and thus membrane conductance in these neurons. This, in turn, reduces the action potential output of the TC neurons, with T-type $\mathrm{Ca} 2+$ channel-mediated high-frequency bursts of action potentials rarely occurring. Importantly, the rhythmic IPSP barrages entrain TC neuron output to cycles of the SWD, providing a sparse but synchronised input to the cortex and maintaining paroxysmal activity within the cortico-thalamo-cortical network.

Acknowledgements Our work in this field is supported by Wellcome Trust (grant 091882), MRC (grant 0900671), European Union (grant
HEALTH F2-2007-202167), ANR MNMP 2009 and CNRS LEA528 (Thalamic function in health and disease states).

\section{References}

1. Avoli M (1995) Feline generalized penicillin epilepsy. Ital J Neurol Sci 16:79-82

2. Avoli M, Gloor P (1981) The effects of transient functional depression of the thalamus on spindles and on bilateral synchronous epileptic discharges of feline generalized penicillin epilepsy. Epilepsia 22:443-452

3. Avoli M, Kostopoulos G (1982) Participation of corticothalamic cells in penicillin-induced generalized spike and wave discharges. Brain Res 247:159-163

4. Bai X, Vestal M, Berman R, Negishi M, Spann M, Vega C, Desalvo M, Novotny EJ, Constable RT, Blumenfeld H (2010) Dynamic time course of typical childhood absence seizures: EEG, behavior, and functional magnetic resonance imaging. The Journal of neuroscience: the official journal of the Society for Neuroscience 30:5884-5893

5. Bal T, Debay D, Destexhe A (2000) Cortical feedback controls the frequency and synchrony of oscillations in the visual thalamus. J Neurosci 20:7478-7488

6. Bal T, von Krosigk M, McCormick DA (1995) Synaptic and membrane mechanisms underlying synchronized oscillations in the ferret lateral geniculate nucleus in vitro. J Physiol (Lond) 483:641-663

7. Bal T, von Krosigk M, McCormick DA (1995) Role of the ferret perigeniculate nucleus in the generation of synchronized oscillations in vitro. J Physiol (Lond) 483:665-685

8. Baldy-Moulinier M (1992) Sleep architecture and childhood absence epilepsy. Epilepsy research. Supplement 6:195-198

9. Batista BH, Nunes ML (2007) Evaluation of sleep habits in children with epilepsy. Epilepsy \& behavior: E\&B 11:60-64

10. Baxter P (2005) Epilepsy and sleep. Dev Med Child Neurol 47:723

11. Bazil CW (2003) Epilepsy and sleep disturbance. Epilepsy \& behavior: E\&B 4(Suppl 2):S39-S45

12. Beenhakker MP, Huguenard JR (2009) Neurons that fire together also conspire together: is normal sleep circuitry hijacked to generate epilepsy? Neuron 62:612-632

13. Bessaïh T, Bourgeais L, Badiu CI, Carter DA, Toth TI, Ruano D, Lambolez B, Crunelli V, Leresche N (2006) Nucleus-specific abnormalities of GABAergic synaptic transmission in a genetic model of absence seizures. J Neurophysiol 96:3074-3081

14. Blethyn KL, Hughes SW, Tóth TI, Cope DW, Crunelli V (2006) Neuronal basis of the slow $(<1 \mathrm{~Hz})$ oscillation in neurons of the nucleus reticularis thalami in vitro. J Neurosci 26:2474-2486

15. Blumenfeld H, McCormick DA (2000) Corticothalamic inputs control the pattern of activity generated in thalamocortical networks. J Neurosci 20:5153-5162

16. Bonjean M, Baker T, Lemieux M, Timofeev I, Sejnowski T, Bazhenov M (2011) Corticothalamic feedback controls sleep spindle duration in vivo. The Journal of neuroscience: the official journal of the Society for Neuroscience 31:9124-9134

17. Bourgeois B (1996) The relationship between sleep and epilepsy in children. Semin Pediatr Neurol 3:29-35

18. Brockhaus J, Pape HC (2011) Abnormalities in GABAergic synaptic transmission of intralaminar thalamic neurons in a genetic rat model of absence epilepsy. Mol Cell Neurosci 46:444-451

19. Byars AW, Byars KC, Johnson CS, DeGrauw TJ, Fastenau PS, Perkins S, Austin JK, Dunn DW (2008) The relationship between sleep problems and neuropsychological functioning in 
children with first recognized seizures. Epilepsy \& behavior: E\&B 13:607-613

20. Castro-Alamancos MA (1999) Neocortical synchronized oscillations induced by thalamic disinhibition in vivo. J Neurosci 19: $\mathrm{RC} 27$

21. Contreras D, Destexhe A, Sejnowski TJ, Steriade M (1996) Control of spatiotemporal coherence of a thalamic oscillation by corticothalamic feedback. Science 274:771-774

22. Contreras D, Destexhe A, Sejnowski TJ, Steriade M (1997) Spatiotemporal patterns of spindle oscillations in cortex and thalamus. J Neurosci 17:1179-1196

23. Contreras D, Steriade M (1996) Spindle oscillation in cats: the role of corticothalamic feedback in a thalamically generated rhythm [published erratum appears in J Physiol (Lond) 1996 Mar 15;491(Pt 3):889]. J Physiol (Lond) 490:159-179

24. Cope DW, Di Giovanni G, Fyson SJ, Orban G, Errington AC, Lorincz ML, Gould TM, Carter DA, Crunelli V (2009) Enhanced tonic GABAA inhibition in typical absence epilepsy. Nat Med 15:1392-1398

25. Crunelli V, Hughes SW (2010) The slow $(<1 \mathrm{~Hz})$ rhythm of nonREM sleep: a dialogue between three cardinal oscillators. Nat Neurosci 13:9-17

26. Crunelli V, Leresche N (2002) Childhood absence epilepsy: genes, channels, neurons and networks. Nat Rev Neurosci 3:371-382

27. Crunelli V, Toth TI, Cope DW, Blethyn K, Hughes SW (2005) The 'window' T-type calcium current in brain dynamics of different behavioural states. J Physiol 562:121-129

28. D'Antuono M, Inaba Y, Biagini G, D'Arcangelo G, Tancredi V, Avoli M (2006) Synaptic hyperexcitability of deep layer neocortical cells in a genetic model of absence seizures. Genes Brain Behav 5:73-84

29. Dreyfus FM, Tscherter A, Errington AC, Renger JJ, Shin HS, Uebele VN, Crunelli V, Lambert RC, Leresche N (2010) Selective T-type calcium channel block in thalamic neurons reveals channel redundancy and physiological impact of $\mathrm{I}(\mathrm{T})$ window. J Neurosci 30:99-109

30. Errington AC, Gibson KM, Crunelli V, Cope DW (2011) Aberrant $\mathrm{GABA}(\mathrm{A})$ receptormediated inhibition in corticothalamic networks of succinic semialdehyde dehydrogenase deficient mice. PLoS One 6:e19021

31. Fisher RS, Prince DA (1977) Spike-wave rhythms in cat cortex induced by parenteral penicillin. I. Electroencephalographic features. Electroencephalogr Clin Neurophysiol 42:608-624

32. Giaretta D, Avoli M, Gloor P (1987) Intracellular recordings in pericruciate neurons during spike and wave discharges of feline generalized penicillin epilepsy. Brain Res 405:68-79

33. Gloor P (1978) Generalized epilepsy with bilateral synchronous spike and wave discharge. New findings concerning its physiological mechanisms. Electroencephalography and clinical neurophysiology. Supplement, pp 245-249

34. Gloor P, Fariello RG (1988) Generalized epilepsy: some of its cellular mechanisms differ from those of focal epilepsy. Trends Neurosci 11:63-68

35. Gotman J, Grova C, Bagshaw A, Kobayashi E, Aghakhani Y, Dubeau F (2005) Generalized epileptic discharges show thalamocortical activation and suspension of the default state of the brain. Proc Natl Acad Sci USA 102:15236-15240

36. Haider B, McCormick DA (2009) Rapid neocortical dynamics: cellular and network mechanisms. Neuron 62:171-189

37. Halasz P, Terzano MG, Parrino L (2002) Spike-wave discharge and the microstructure of sleep-wake continuum in idiopathic generalised epilepsy. Neurophysiologie clinique $=$ Clinical neurophysiology 32:38-53

38. Hoffman KL, Battaglia FP, Harris K, MacLean JN, Marshall L, Mehta MR (2007) The upshot of up states in the neocortex: from slow oscillations to memory formation. The Journal of neuroscience: the official journal of the Society for Neuroscience 27:11838-11841

39. Holmes MD, Brown M, Tucker DM (2004) Are "generalized" seizures truly generalized? Evidence of localized mesial frontal and frontopolar discharges in absence. Epilepsia 45:1568-1579

40. Horita H (2001) Epileptic seizures and sleep-wake rhythm. Psychiatry Clin Neurosci 55:171-172

41. Hughes SW, Cope DW, Blethyn KL, Crunelli V (2002) Cellular mechanisms of the slow $(1 \mathrm{~Hz})$ oscillation in thalamocortical neurons in vitro. Neuron 33:947-958

42. Huguenard JR, McCormick DA (2007) Thalamic synchrony and dynamic regulation of global forebrain oscillations. Trends Neurosci 30:350-356

43. Huguenard JR, Prince DA (1994) Intrathalamic rhythmicity studied in vitro: nominal T-current modulation causes robust antioscillatory effects. J Neurosci 14:5485-5502

44. Hunter J, Jasper H (1948) Reactions of unanaesthetised animals to thalamic stimulation. Trans Am Neurol Assoc 73:171

45. Huntsman MM, Porcello DM, Homanics GE, DeLorey TM, Huguenard JR (1999) Reciprocal inhibitory connections and network synchrony in the mammalian thalamus. Science 283:541-543

46. Jando G, Carpi D, Kandel A, Urioste R, Horvath Z, Pierre E, Vadi D, Vadasz C, Buzsaki G (1995) Spike-and-wave epilepsy in rats: sex differences and inheritance of physiological traits. Neuroscience 64:301-317

47. Kananura C, Haug K, Sander T, Runge U, Gu W, Hallmann K, Rebstock J, Heils A, Steinlein OK (2002) A splice-site mutation in GABRG2 associated with childhood absence epilepsy and febrile convulsions. Arch Neurol 59:1137-1141

48. Kandel A, Buzsaki G (1997) Cellular-synaptic generation of sleep spindles, spike-and-wave discharges, and evoked thalamocortical responses in the neocortex of the rat. The Journal of neuroscience: the official journal of the Society for Neuroscience 17:6783-6797

49. Kellaway P (1985) Childhood seizures. Electroencephalography and clinical neurophysiology. Supplement 37:267-283

50. Kellaway P (1985) Sleep and epilepsy. Epilepsia 26(Suppl 1): S15-S30

51. Kellaway P, Frost JD Jr, Crawley JW (1980) Time modulation of spike-and-wave activity in generalized epilepsy. Ann Neurol 8:491-500

52. Killory BD, Bai X, Negishi M, Vega C, Spann MN, Vestal M, Guo J, Berman R, Danielson N, Trejo J, Shisler D, Novotny EJ Jr, Constable RT, Blumenfeld H (2011) Impaired attention and network connectivity in childhood absence epilepsy. Neuroimage 76:1960-1967

53. Kim U, Sanchez-Vives MV, McCormick DA (1997) Functional dynamics of GABAergic inhibition in the thalamus. Science 278:130-134

54. Kostopoulos GK (2000) Spike-and-wave discharges of absence seizures as a transformation of sleep spindles: the continuing development of a hypothesis. Clinical neurophysiology: Official Journal of the International Federation of Clinical Neurophysiology 111(Suppl 2):S27-S38

55. Kostopoulos G, Gloor P, Pellegrini A, Gotman J (1981) A study of the transition from spindles to spike and wave discharge in feline generalized penicillin epilepsy: microphysiological features. Exp Neurol 73:55-77

56. Kostopoulos G, Gloor P, Pellegrini A, Siatitsas I (1981) A study of the transition from spindles to spike and wave discharge in feline generalized penicillin epilepsy: EEG features. Exp Neurol 73:43-54

57. Kotagal P, Yardi N (2008) The relationship between sleep and epilepsy. Semin Pediatr Neurol 15:42-49 
58. Lachance-Touchette P, Brown P, Meloche C, Kinirons P, Lapointe L, Lacasse H, Lortie A, Carmant L, Bedford F, Bowie D, Cossette P (2011) Novel alpha1 and gamma2 GABA(A) receptor subunit mutations in families with idiopathic generalized epilepsy. Eur J Neurosci 34:237-249

59. Lannes B, Micheletti G, Vergnes M, Marescaux C, Depaulis A, Warter JM (1988) Relationship between spike-wave discharges and vigilance levels in rats with spontaneous petit mal-like epilepsy. Neurosci Lett 94:187-191

60. Loddenkemper $T$, Vendrame $M$, Zarowski $M$, Gregas $M$, Alexopoulos AV, Wyllie E, Kothare SV (2011) Circadian patterns of pediatric seizures. Neurology 76:145-153

61. Lonjers P, Timofeev I, Chen J-Y, Bazhenov M (2010) The roles of thalamocortical input in generating slow sleep oscillations. Soc. Neurosc. Abstr. pp. 552.18

62. Luhmann HJ, Mittmann T, van Luijtelaar G, Heinemann U (1995) Impairment of intracortical GABAergic inhibition in a rat model of absence epilepsy. Epilepsy Res 22:43-51

63. Macdonald RL, Kang JQ, Gallagher MJ (2010) Mutations in GABAA receptor subunits associated with genetic epilepsies. J Physiol 588:1861-1869

64. Maljevic S, Krampfl K, Cobilanschi J, Tilgen N, Beyer S, Weber YG, Schlesinger F, Ursu D, Melzer W, Cossette P, Bufler J, Lerche $\mathrm{H}$, Heils A (2006) A mutation in the GABA(A) receptor alpha(1)subunit is associated with absence epilepsy. Ann Neurol 59: 983-987

65. Manning JA, Richards DA, Leresche N, Crunelli V, Bowery NG (2004) Cortical-area specific block of genetically determined absence seizures by ethosuximide. Neuroscience 123:5-9

66. Marescaux C, Vergnes M, Depaulis A (1992) Genetic absence epilepsy in rats from Strasbourg - a review. J Neural Transm Suppl 35:37-69

67. McCormick DA, Bal T (1997) Sleep and arousal: thalamocortical mechanisms. Annu Rev Neurosci 20:185-215

68. McCormick DA, Contreras D (2001) On the cellular and network bases of epileptic seizures. Annu Rev Physiol 63: $815-846$

69. Meeren HK, Pijn JP, Van Luijtelaar EL, Coenen AM, Lopes da Silva FH (2002) Cortical focus drives widespread corticothalamic networks during spontaneous absence seizures in rats. J Neurosci 22:1480-1495

70. Meeren HK, Veening JG, Moderscheim TA, Coenen AM, van Luijtelaar G (2009) Thalamic lesions in a genetic rat model of absence epilepsy: dissociation between spikewave discharges and sleep spindles. Exp Neurol 217:25-37

71. Mehta MR (2007) Cortico-hippocampal interaction during updown states and memory consolidation. Nat Neurosci 10:13-15

72. Moeller F, LeVan P, Muhle H, Stephani U, Dubeau F, Siniatchkin M, Gotman J (2010) Absence seizures: individual patterns revealed by EEG-fMRI. Epilepsia 51:2000-2010

73. Myatchin I, Lagae L (2007) Sleep spindle abnormalities in children with generalized spike-wave discharges. Pediatr Neurol 36:106-111

74. Niedermeyer E (1996) Primary (idiopathic) generalized epilepsy and underlying mechanisms. Clin Electroencephalogr 27:1-21

75. Nobili L, Baglietto MG, Beelke M, De Carli F, Veneselli E, Ferrillo F (2001) Temporal relationship of generalized epileptiform discharges to spindle frequency activity in childhood absence epilepsy. Clinical neurophysiology: Official Journal of the International Federation of Clinical Neurophysiology 112:1912-1916

76. Panayiotopoulos CP (2001) Treatment of typical absence seizures and related epileptic syndromes. Paediatr Drugs 3:379-403

77. Panyiotopoulos CP (1997) Absences epilepsies. In: Engel JJ, Pedley TA (eds) Epilepy: a Comprehensive Textbook. LippicottRaven, Philadelphia, pp 2327-2346
78. Paz JT, Chavez M, Saillet S, Deniau JM, Charpier S (2007) Activity of ventral medial thalamic neurons during absence seizures and modulation of cortical paroxysms by the nigrothalamic pathway. J Neurosci 27:929-941

79. Pinault D, Leresche N, Charpier S, Deniau JM, Marescaux C, Vergnes M, Crunelli V (1998) Intracellular recordings in thalamic neurones during spontaneous spike and wave discharges in rats with absence epilepsy. J Physiol (Lond) 509:449-456

80. Pinault D, Slezia A, Acsady L (2006) Corticothalamic 5-9 Hz oscillations are more proepileptogenic than sleep spindles in rats. J Physiol 574:209-227

81. Pinault D, Vergnes M, Marescaux C (2001) Medium-voltage 5-9-Hz oscillations give rise to spike-and-wave discharges in a genetic model of absence epilepsy: in vivo dual extracellular recording of thalamic relay and reticular neurons. Neuroscience 105:181-201

82. Polack PO, Guillemain I, Hu E, Deransart C, Depaulis A, Charpier S (2007) Deep layer somatosensory cortical neurons initiate spike-and-wave discharges in a genetic model of absence seizures. J Neurosci 27:6590-6599

83. Prince DA, Farrell D (1969) "Centrencephalic" spike-wave discharges following parental penicillin injection in the cat. Neurology 19:309-310

84. Röder U, Wolf P (1981) Effect of treatment of dipropylacetate and ethosuximide on sleep organization in epileptic patients. Raven Press, New York

85. Schofield CM, Kleiman-Weiner M, Rudolph U, Huguenard JR (2009) A gain in GABAA receptor synaptic strength in thalamus reduces oscillatory activity and absence seizures. Proc Natl Acad Sci USA 106:7630-7635

86. Sitnikova E, van Luijtelaar G (2007) Electroencephalographic characterization of spikewave discharges in cortex and thalamus in WAG/Rij rats. Epilepsia 48:2296-2311

87. Slaght SJ, Leresche N, Deniau JM, Crunelli V, Charpier S (2002) Activity of thalamic reticular neurons during spontaneous genetically determined spike and wave discharges. J Neurosci 22:2323-2334

88. Smyk MK, Coenen AM, Lewandowski MH, van Luijtelaar G (2011) Endogenous rhythm of absence epilepsy: relationship with general motor activity and sleep-wake states. Epilepsy Res 93:120-127

89. Staak R, Pape HC (2001) Contribution of GABA(A) and GABA (B) receptors to thalamic neuronal activity during spontaneous absence seizures in rats. The Journal of neuroscience: the official journal of the Society for Neuroscience 21:1378-1384

90. Steriade M, Contreras D (1995) Relations between cortical and thalamic cellular events during transition from sleep patterns to paroxysmal activity. J Neurosci 15:623-642

91. Steriade M, Contreras D (1998) Spike-wave complexes and fast components of cortically generated seizures. I. Role of neocortex and thalamus. J Neurophysiol 80:1439-1455

92. Steriade M, Contreras D, Amzica F (1994) Synchronized sleep oscillations and their paroxysmal developments. Trends Neurosci 17:199-208

93. Steriade M, Deschenes M, Domich L, Mulle C (1985) Abolition of spindle oscillations in thalamic neurons disconnected from nucleus reticularis thalami. J Neurophysiol 54:1473-1497

94. Steriade M, McCormick DA, Sejnowski TJ (1993) Thalamocortical oscillations in the sleeping and aroused brain. Science 262:679-685

95. Suntsova N, Kumar S, Guzman-Marin R, Alam MN, Szymusiak R, McGinty D (2009) A role for the preoptic sleep-promoting system in absence epilepsy. Neurobiol Dis 36:126-141

96. Tan HO, Reid CA, Chiu C, Jones MV, Petrou S (2008) Increased thalamic inhibition in the absence seizure prone DBA/2J mouse. Epilepsia 49:921-925

97. Tan HO, Reid CA, Single FN, Davies PJ, Chiu C, Murphy S, Clarke AL, Dibbens L, Krestel H, Mulley JC, Jones MV, Seeburg 
PH, Sakmann B, Berkovic SF, Sprengel R, Petrou S (2007) Reduced cortical inhibition in a mouse model of familial childhood absence epilepsy. Proc Natl Acad Sci USA 104:17536-17541

98. Tanaka M, Olsen RW, Medina MT, Schwartz E, Alonso ME, Duron RM, Castro-Ortega R, Martinez-Juarez IE, PascualCastroviejo I, Machado-Salas J, Silva R, Bailey JN, Bai D, Ochoa A, Jara-Prado A, Pineda G, Macdonald RL, DelgadoEscueta AV (2008) Hyperglycosylation and reduced GABA currents of mutated GABRB3 polypeptide in remitting childhood absence epilepsy. Am J Hum Genet 82:1249-1261

99. Tononi G, Massimini M, Riedner BA (2006) Sleepy dialogues between cortex and hippocampus: who talks to whom? Neuron $52: 748-749$

100. Tyvaert L, Chassagnon S, Sadikot A, LeVan P, Dubeau F, Gotman J (2009) Thalamic nuclei activity in idiopathic generalized epilepsy: an EEG-fMRI study. Neurology 73:2018-2022

101. van Luijtelaar G, Bikbaev A (2007) Midfrequency corticothalamic oscillations and the sleep cycle: genetic, time of day and age effects. Epilepsy Res 73:259-265

102. van Luijtelaar G, Hramov A, Sitnikova E, Koronovskii A (2011) Spike-wave discharges in WAG/Rij rats are preceded by delta and theta precursor activity in cortex and thalamus. Clinical neurophysiology: official journal of the International Federation of Clinical Neurophysiology 122:687-695

103. Vaudano AE, Laufs H, Kiebel SJ, Carmichael DW, Hamandi K, Guye M, Thornton R, Rodionov R, Friston KJ, Duncan JS,
Lemieux L (2009) Causal hierarchy within the thalamocortical network in spike and wave discharges. PLoS One 4:e6475

104. Vergnes M, Marescaux C (1992) Cortical and thalamic lesions in rats with genetic absence epilepsy. J Neural Transm Suppl 35:71-83

105. von Krosigk M, Bal T, McCormick DA (1993) Cellular mechanisms of a synchronized oscillation in the thalamus. Science 261:361-364

106. Wallace RH, Marini C, Petrou S, Harkin LA, Bowser DN, Panchal RG, Williams DA, Sutherland GR, Mulley JC, Scheffer IE, Berkovic SF (2001) Mutant GABA(A) receptor gamma2subunit in childhood absence epilepsy and febrile seizures. Nat Genet 28:49-52

107. Westmijse I, Ossenblok P, Gunning B, van Luijtelaar G (2009) Onset and propagation of spike and slow wave discharges in human absence epilepsy: A MEG study. Epilepsia 50:25382548

108. Williams D (1953) A study of thalamic and cortical rhythms in petit mal. Brain: a journal of neurology 76:50-69

109. Wirrell E, Blackman M, Barlow K, Mah J, Hamiwka L (2005) Sleep disturbances in children with epilepsy compared with their nearest-aged siblings. Dev Med Child Neurol 47:754-759

110. Zarowski M, Loddenkemper T, Vendrame M, Alexopoulos AV, Wyllie E, Kothare SV (2011) Circadian distribution and sleep/ wake patterns of generalized seizures in children. Epilepsia 52:1076-1083 